\title{
Psychogenic Nonepileptic Seizures
}

\author{
Journal of \\ Epilepsy and \\ Clinical \\ Neurophysiology
}

J Epilepsy Clin Neurophysiol 2007; 13(4, Suppl 1):7-9

\section{Psychogenic Nonepileptic Seizures: An Overview}

\author{
Luciano De Paola*, Carlos Silvado**, Maria Joana Mäder-Joaquim***, Ana Crippa**** \\ Programa de Cirurgia de Epilepsia - Hospital de Clínicas da Universidade Federal do Paraná
}

\begin{abstract}
Pyschogenic nonepileptic seizures (PNES) are common and potentially harmful - both physically and emotionally - events. They are often under or misdiagnosed. Not only neurologists managing epilepsy, but also generalists and ER physicians should be aware of its existence, preventing unnecessary tests, as well as, iatrogenic interventions. The assistance provided to these patients is often inadequate, even at larger and busier epilepsy centers. That clearly impacts on the prognosis of this condition, which is fairly difficult to manage per se, yet with the best possible quality of care, including well trained multiprofessional teams.
\end{abstract}

Key words: psychogenic nonepileptic seizures, psychiatric comorbidities in epilepsy.

\section{RESUMO}

Crises não-epilépticas psicogênicas: uma revisão

Crises não-epilépticas psicogênicas (CNEP) são eventos comuns e potencialmente prejudiciais, tanto física quanto emocionalmente. São comumente subdiagnosticas ou mesmo diagnosticas erroneamente. Não apenas neurologistas envolvidos com o tratamento de epilepsia, mas também clínicos gerais e principalmente médicos em unidades de emergência deveriam estar cientes de sua existência, evitando exames desnecessários e possível iatrogênese. A assistência a estes pacientes é frequentemente inadequada, mesmo em grandes centros de atendimento a epilepsia, aspecto que impacta de forma definitiva no prognóstico destes pacientes. O manejo destes casos é habitualmente difícil, mesmo em ambientes com equipes multiprofissionais bem treinadas com este propósito.

Unitermos: crises não-epilépticas psicogênicas, comorbidades psiquiátricas em epilepsia.

Psychogenic nonepileptic seizures (PNES) are paroxysmal events that resemble epileptic seizures but lack organic substrate. Acknowledgment of psychogenic phenomena is supported by fairly consistent descriptions since Hypocrates (-400 BC) and Araeteus (-200 BC) and later on by Gowers and Charcot (at the end of XIX Century), just to allude to the classic reports. ${ }^{1}$ Terminology maybe differ according to their time, but in common, they all attempted to distinguish "epileptic seizures" from episodes often described as "hysteria". And they did it quite succesfully - by the means of pure observation of the clinical expression on such events. Now, why would they and others to follow develop such interest on these patients and their intriguing "seizures"? It could certainly be the clinical exuberance of these episodes, their elevated recurrence rates or the difficult management of such ca-

\footnotetext{
* Diretor Científico, Programa de Cirurgia de Epilepsia HC-UFPR.

** Professor Adjunto de Neurologia HC-UFPR, Diretor Técnico do Programa de Cirurgia de Epilepsia HC-UFPR.

*** Neuropsicóloga do Programa de Cirurgia de Epilepsia HC-UFPR.

**** Neuropediatra do Programa de Cirurgia de Epilepsia HC-UFPR.

Received Nov. 30, 2007; accepted Dec. 14, 2007.
} 
ses. Those were good as reasons then, as they remain excellent motivation for research today. However, their attention might have been triggered the notion of how frequent these "seizures" were observed on patients, particularly the institutionalized ones. In fact, it was later understood that psychogenic symptoms may represent $1 \%$ of overall neurological care ${ }^{2}$ and up to $10 \%$ of all neurological cases at the inpatient setting. ${ }^{3}$ Specifically, an estimate of the prevalence of PNES suggests figures in the vicinity of 2-33 individuals per 100.000, which makes this condition a highly interesting neuropsychiatric diagnosis. ${ }^{4}$ At the epilepsy clinic up to $20 \%$ of the patients may present with PNES and this might escalate to $40 \%$ in the setting of a tertiary epilepsy center ${ }^{5}$. The coexistence of epileptic and PNES varies according to different authors with citations between 10 and 50\%. ${ }^{6}$ Such discrepancy may be related to the analysis of distinct populations and the use of different criteria and methodology. The undisputed fact, however, is the prevalence of women with the diagnosis of PNES with a 1:4 proportion likely to represent an honest estimate. $^{?}$

Understanding (and accepting) the high prevalence of PNES is pivotal in its care. That makes one aware of the condition and may prevent at least two undesirable consequences of neglecting this diagnostic hypothesis. First, because of their often alarming presentation, patients with PNES are frequently referred to emergency rooms where they are prone to iatrogenic procedures. "Status epilepticus" is not an uncommon diagnosis on these patients and massive doses of diazepinics or phenytoin may be unnecessarily used. There is at least one report of a deadly consequence in a 17 years old young man misinterpreted as "status epilepticus" (being in fact a factitious disorder) and going into electromechanical dissociation and irrecoverable cardiorespiratory arrest following a phenytoin load. ${ }^{8}$ Secondly, PNES may cost US\$ 100-900 million (per year) in equivocal procedures and treatments intended to treat wrongfully diagnosed "epilepsy". ${ }^{9}$

Hence, how to establish the correct diagnosis of PNES? That is certainly not always a straight forward task. A set of clinical features may help inducing the suspicion of PNES based on history, including emotional trigger factors, elevated seizure frequency that is never changed by medication, seizures that are never witnessed, lack of physical trauma in somewhat aggressive seizures, expressing excessive concern or - on the contrary - lack of concern regarding seizures, history of sexual abuse and the history of repeatedly normal tests on multiple evaluations for epilepsy. In witnessed or recorded seizures, the nonphysiological progression of movements, out-ofphase movements, extremely prolonged dystonic posturing or even opisthotonus, eyes kept closed throughout the entire event or seizures induced by suggestion are among the semiological features to take in account for the diagnosis of PNES. VideoEEG documentation of the suspicious events remains the gold-standard diagnostic tool for confirmation of PNES. It is important to keep in mind the need to record - whenever technically possible - all the suspicious events, given the possibility that some of them may indeed represent legit epileptic seizures in a so called "mixed" patient (with epileptic, as well as, PNES). Hormonal testing - i.e, the premise of prolactin elevation in epileptic seizures and not on PNES - is disputed on different epilepsy centers as a valid diagnostic tool for PNES. Pregnancy, lactation, sexual activity, breast manipulation and the use of several drugs may interfere on prolactin levels jeopardizing its diagnostic value in this setting. There are also reservations about inducing procedures on distinct epilepsy centers. Avoiding a trust breach between the attending physician and the patients and their families is what prevents inducing PNES in some institutions. The rational for its use, however, is that inducing procedures are considered effective in $30-100 \%$ of the attempted cases, which clearly justifies its recommendation in some protocols. ${ }^{10}$

If diagnosing PNES may impose a bit of a problem in many patients, trying to understand what is behind these events - or their neurobiological basis - constitutes a true challenge. In "mixed" patients (presenting with both epileptic and PNES) it is very tempting to blame it on psychiatric phenomena that is extremely prevalent in people with epilepsy with an increase of at least two-fold compared to the general population. However, psychiatric symptoms may or may not have a time-locked relation to epileptic phenomena. A multiplicity of diagnostic instruments is available and may be used on clearly nonhomogeneous populations leading to conflicting results. Finally, there may very well be specific psychiatric disorders of epilepsy which are not sensible to the available instruments and scales ${ }^{11}$. Evidently in "pure" patients (i.e., where PNES are the only presentation) there is rich psychopathology justifying the events. Dealing with the psychiatric diagnosis in this condition however, has proved to be a complex task. There have been attempts to a systematic classification of PNES based on DSM-IV criteria $^{12,13}$. Somatoform disorders are largely the basis for PNES, particularly of the conversion type. Dissociation disorders represent a group considered by many "essential" in the diagnosis of PNES as it encompasses conditions in which there is fragmentation of consciousness, memory, identity and environment perception, phenomena commonly seen on "epileptic-like" seizures. Finally, the clear intention to produce symptoms - with either an obvious or more obscure secondary gain - as seen on malingering and factitious disorder, respectively is an often difficult to recognize feature in these conditions. 
Posttraumatic Stress Disorder (PTSD) may be key in the diagnosis of PNES. This fascinating experience involves being exposed to or having witnessed a dramatic episode cursing with the potential risk of death or severe injure. The concept requires that the individual exposed perceives intense fear, horror or hopelessness, feelings to be reenacted on situations to follow. History of some sort of trauma may be obtained on $40-100 \%$ of PNES patients, as is the case with abuse, on $20-70 \%$ of the cases. ${ }^{14}$ Specific patterns of stress responses are likely to explain the development of PTSD, with citations on hormonal, genetic and anatomic - among other - clinical evidences.

Diagnosing PNES carries elements of technicality and a systematic approach tends to facilitate this effort. On the other hand, delivering the diagnosis to patients and families and later on trying to treat these cases is often difficult. Prognosis on these patients varies according to the psychopathology involved, as well as, the level of care and specialized support available in each setting. The literature expresses such differences, alluding to a broad range ( 25 to $87 \%$ ) of favorable prognosis. ${ }^{15}$ No doubt these discrepant figures are related to variations on therapeutic protocols but also on the concept of what is considered a "good" prognosis.

To conclude, PNES are common and potentially harmful - both physically and emotionally - events. They are often under or misdiagnosed. Not only neurologists managing epilepsy, but also generalists and ER physicians should be aware of its existence, preventing unnecessary tests and iatrogenic interventions. The assistance provided to these patients is often inadequate, even on larger and busier epilepsy centers. That clearly impacts on the prognosis on this population, which is fairly difficult to manage per se, yet with the best possible quality of care, including well trained multiprofessional teams.

\section{REFERENCES}

1. Gates JR, Ramani V, Whalen S et al. Ictal characteristics of pseudoseizures. Arch Neurol. 1985;42:1183-7.

2. Marden CS. Hysteria: A neurologist's view. Psychological Medicine. 1986;16:277-88.

3. Lempert T, Dietrich M, Huppert D et al. Pyschogenic disorders in neurology: Frequency and clinical spectrum. Acta Neurol Scand. 1990;82:335-40.

4. Benbadis SR, Hauser WA. An Estimate of the prevalence of psychogenic nonepileptic seizures. Seizure. 2000;9:280-1.

5. Gates JR. Psychiatric aspects of nonepileptic seizures. In: Imitators of epilepsy. $2^{\text {nd }}$ ed. (Editado por Peter W Kaplan, MB, FRCP and Robert S Fischer, MD, PhD; p. 255-60). New York: Demos; 2005.

6. Benbadis SR, Agrawal V, Tatum WO. How many patients with psychogenic nonepileptic seizures also have epilepsy? Neurology. 2001;57:915-917.

7. De Paola L, Silvado CE, Mader MJ et al. Clinical features of psychogenic nonepileptic seizures (PNES): Analysis of a brazilian series. JECN. 2006;12:649-651.

8. Reuber M, Baker GA, Gill R et al. Failure to recognize psychogenic nonepileptic seizures may cause death. Neurology. 2004;62:834-835.

9. LaFrance WC, Benbadis SR. Avoiding the costs of unrecognized psychogenic nonepileptic seizures. Neurology. 2006;66:1620-1.

10. De Paola L. Crises não-epilépticas. Em tratamento clínico e cirúrgico das epilepsias de difícil controle (Editado por Artur Cukiert; p. 201-12). São Paulo: Lemos Editorial; 2002.

11. Gaitatzis A, Carrol K, Majeed JW et al. The epidemiology of comorbidity of epilepsy in the general population. Epilepsia. 2004;45:1613-22.

12. Gates JR. Classification and differential diagnosis. In: Nonepileptic events (pseudoseizures). New York: American Academy of Neurology (syllabus); 1993.

13. Gates JR, Mercer K. Nonepileptic Events. Semin Neurol. 1995;15(2):167-73.

14. Fiszman A, Alves-Leon SV, Nunes RG et al. Traumatic events and posttraumatic stress disorder in patients with psychogenic nonepileptic seizures: A critical review. Epilepsy and Behavior. 2004;5:818-25.

15. Doherty K, Mason S, Gates JR. Psychogenic nonepileptic seizures (pseudoseizures): prognosis after inpatient evaluation. Epilepsia. 1993;34(suppl 6):26.

Main author correspondence:

Luciano De Paola

Serviço de EEG - Hospital de Clínicas - UFPR

Rua General Carneiro, 180

CEP 80060-900, Curitiba, PR, Brasil

E-mail:1lpaola@mps.com.br 